\title{
Um passeio pelo bosque da filosofia: Yves Schwartz, um pensador da atividade humana, sempre inédita e regida por valores
}

Resumo: O filosofo e professor Yves Schwartz, diretor do Departamento de Ergologia da Universidade de Provence, fala sobre trabalho, um tema pouco palatável e que a maioria de nós assemelha a sofrimento, disciplina, reclusão etc. $O$ filósofo, instigado pelo tema da formação continuada de trabalhadores, relata como se apropriou de um novo saber e o retornou à academia para criar um dispositivo capaz de problematizar, no nível teórico e prático, quais são os saberes do trabalho, o que é a educação ou a formação para o trabalho, o que significa geri-lo, o que é o trabalho e o que se cria entre os indivíduos no mundo do trabalho. Sua proposta de dispositivo de análise e de abordagem da atividade de trabalho tem contribuído a diferentes campos do saber, além da Filosofia: à Educação, à Saúde, à Gestão, à Engenharia, à Sociologia e também à Comunicação.

Palavras-chave: trabalho, atividade, ergologia, educação continuada, comunicação.
Abstract: The philosopher and teacher Yves Schwartz, director of the University not palatable subject that most people associate to distress, control, reclusion etc. The philosopher, instigated by the theme of workers continued education, tells us how he has appropriated a new knowledge and brought it to academy to create a device to problematize, at theoretical and practical levels, learning's of work, education or formation for work, work management, the work itself and what is created among individuals in the world of work. His proposal of analysis device and approach of the working activity has brought contributions to several fields of knowledge besides Philosophy: Education, Health, Management, Engineering, Sociology and Communication.

Keywords: work, activity, Ergology, continued education, communication.
Recebido: 20/02/2008

Aprovado: 16/03/2008 
O filósofo e professor Yves Schwartz, diretor do Departamento de Ergologia da Universidade de Provence, fala a Comunicação \& Educação sobre trabalho, um tema pouco palatável e que a maioria de nós assemelha a sofrimento, disciplina, reclusão etc. O filósofo, de formação clássica, que teve Louis Althusser e George Canguilhem como referencias na École Normale Supérieure, em Paris, instigado pelo tema da formação continuada de trabalhadores adultos, entra no mundo do trabalho industrial como militante e sindicalista; e, em conjunto com eles, apropria-se de um novo saber: o do trabalho real, aquele que se efetiva entre o prescrito e o possível de ser realizado, totalmente dependente da atividade inusitada do indivíduo e de sua coletividade no mundo laboral. De posse desse saber, o filósofo retorna à academia para criar um dispositivo capaz de problematizar, no nível teórico e prático, quais são os saberes do trabalho, o que é a educação ou a formação para o trabalho, o que significa geri-lo, o que é o trabalho e o que se cria entre os indivíduos no mundo do trabalho. As contribuições do prof. Schwartz estão sistematizadas em vários de seus livros" e pelos estudantes e profissionais que formou na França, no Brasil, na Bélgica, em Portugal, Moçambique, Camarões e em outros países. Sua proposta de dispositivo de análise e de abordagem da atividade de trabalho tem dado contribuições a diferentes campos do saber, além da Filosofia: à Educação, à Saúde, à Gestão, à Engenharia, à Sociologia e também à Comunicação. Comunicação \& Educação publica parte da entrevista exclusiva concedida pelo professor, na Universidade de Provence.

Por Roseli Fígaro

C\&E: Gostaria que o senhor falasse sobre sua trajetória pessoal e acadêmica para que possamos conhecê-lo melhor.

Schwartz: A minha trajetória pessoal e acadêmica?

C\&E: Sim. Sua história de vida, sua formação. O senhor fez Filosofia?

Schwartz: Por um lado, acho que tenho uma formação muito clássica. Vivi em Paris e segui estudos clássicos no Lycée de Paris; depois fui aluno na École Normale Supérieure, o que supõe uma formação, como se costuma dizer, humanista. A minha família era composta de científicos: matemáticos, engenheiros, médicos; fui o primeiro a fazer esse desvio... para as humanidades. Estava hesitando entre a História e a Filosofia, porque as duas me encantavam. Quando coloquei a pergunta ao

* Autor de extensa obra em língua francesa, tem publicado em português contribuições na revista Proposições, da Faculdade de Educação da Unicamp, e na Revista Saúde, Trabalho e Educação, da Fiocruz. Outras publicações em português, ver SILVA, Maria Cecília Pérez de Souza E.; FAÏTA, Daniel. (Orgs.). Linguagem e trabalho: construção de objetos de análise no Brasil e na França. São Paulo: Cortez, 2002. (N.E.)

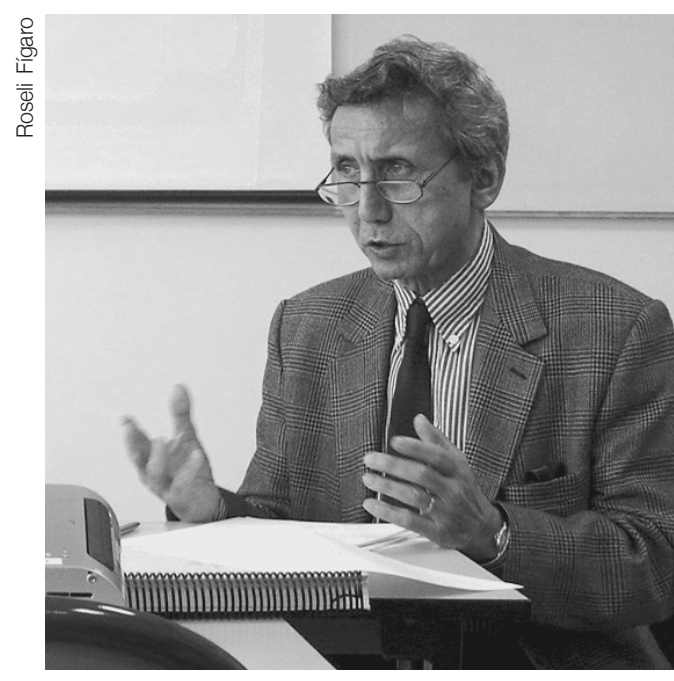


C\&E: O senhor, depois de formado como filósofo, continuou na universidade ou trabalhou em outros lugares, em outras instituições?

Schwartz: É aqui que começa a ser um pouco complicado! Especializei-me em Filosofia das Ciências da Epistemologia com o prestigiado professor George Canguilhem, na época presidente da Escola Normal Superior, e nos movimentados anos de 1968. Depois acompanhei minha esposa, pois ela havia sido escolhida para ensinar na Universidade de Provence. Lá, rapidamente, também obtive um cargo de ensino e, de certa maneira, fiz toda minha carreira nesta instituição. Parece muito simples, mas... depois comecei a me interessar pelas questões de formação continuada, possibilidade aberta aos trabalhadores franceses a partir dos anos 1970. Atraiu-me as relações entre a universidade e o mundo das atividades econômicas e do trabalho. A partir daí, minha trajetória foi bastante atípica. Afastei-me durante três anos do Departamento de Filosofia para criar relações entre a universidade e as instituições de trabalhadores, as mais diversas, para melhor entender quais poderiam ser as formações contínuas a serem desenvolvidas e ensinadas aos trabalhadores na universidade. De certa maneira, fui realizar a aprendizagem de um mundo que eu não conhecia bem. Foi uma experiência rica; são dois universos cheios de questões específicas, de contradições: as relações entre as atividades econômicas do mundo do trabalho e o mundo do saber acadêmico eram bem complicadas, e fui me engajando, comprometido com uma trajetória sindical, política, durante anos. Isso possibilitou entranhar-me melhor, aprofundar-me no real do mundo do trabalho, e me afastou muito da carreira acadêmica tradicional, porque, embora na universidade, fiquei quinze anos sem voltar ao Departamento de Filosofia. Ao mesmo tempo, continuei o trabalho sobre História das Ciências, Histórias das Técnicas e sobre as questões históricas do trabalho. No início dos anos 1990, esse interesse pelas relações entre $o$ saber e $o$ trabalhar e a formação continuada me fizeram voltar à academia. Comecei a escrever minha tese, reinseri-me nos cursos universitários e na pesquisa para criar um dispositivo capaz de refletir sobre tal relação, integrando essa minha trajetória atípica; daí vem todo esse percurso que conduziu à criação do Departamento de Ergologia da Universidade de Provence.

C\&E: É bastante coerente sua proposta no ensino universitário com sua vida, porque o senhor disse que recebeu uma formação tipicamente clássica, mas também viveu uma experiência, uma imersão no mundo do trabalho muito ampla e longa que pôde resultar em vivência concreta para melhor amadurecer uma proposta teórica e de ensino na academia. Hoje é tão complicado o tema do trabalho na sociedade! Mesmo os sociólogos tratam do tema numa disciplina: a Sociologia do Trabalho; a Economia também não se interessa muito pelo trabalho, mas pelas finanças. Como é que um filósofo se interessa pelo trabalho? Como é isso dentro da universidade?

Schwartz: Estamos sempre aprendendo o que é a Filosofia, nunca estamos filósofos; estamos sempre em trânsito, sempre como aprendizes. Nossa ambição é a de empregar melhor nossa capacidade de conceituar, que é característica 
de todo ser humano, e utilizá-la de um jeito sábio, sem derivar, sem mutilar, se é que você entende o que quero dizer. Desde os anos 1968, toda aquela movimentação sobre o trabalho e a influência de uma pessoa tão fascinante como Louis Althusser nos revelavam a questão do que primeiramente chamei o mundo do trabalho e o mundo da fabricação do saber na universidade. Havia um descaso ali, um descompasso... as relações não eram sadias. Faltava alguma coisa ao saber universitário ao conceituar o ato de trabalhar. Não sabíamos o quê, mas se pudéssemos avaliar, conhecer do que se tratava... Claro que essa questão de bem ou mal conceituar é uma questão inteiramente filosófica. Era uma maneira de entender o ensino de George Canguilhem, que nos aconselhava a enfrentar o que ele chamou de matérias estrangeiras (matières étrangères). Para ele, a técnica, o ato técnico, por exemplo, era muito rico do ponto de vista filosófico, mas é claro que essa não era uma preocupação bem difundida através dos aprendizes de Filosofia. Por isso, as questões do fazer técnico, do fazer industrioso do trabalho pareciam uma matéria estrangeira a ser mais bem atravessada para se dizer alguma coisa de pertinente sobre o ser humano, a história humana, o corpo humano. E foi aí que, simultaneamente, esta experiência mais militante me fez conhecer o mundo técnico, o mundo do trabalho, o que me parecia um rumo a cumprir, uma exigência filosófica. Essa trajetória, para mim, era sempre o cumprimento parcial da missão, da vocação filosófica, mesmo que isso não fosse bem compreendido pelos outros, pelos colegas, pelos amigos filósofos.

C\&E: O problema do status na academia também é uma coisa séria entre os pares, e isso o senhor deve sentir muito, não é? No Brasil, por exemplo, há temas que ainda não são muito bem-vistos; não sei se na França é da mesma forma. Essas coisas também devem acontecer com o senhor.

Schwartz: Muito, muito. Claro que esse tipo de dificuldade ligada a status foi a origem de muitas dificuldades através de todos estes anos. Não vou tratar disso, mas graças à confiança de gente como George Canguilhem, por exemplo, foi possível continuar. Por meio desta questão do trabalho, emergia uma questão mais abrangente, a que chamamos atividade, no sentido ergológico. Hoje não é tão difícil demonstrar que, a partir do trabalho como ponto de partida, questões claramente filosóficas podem ser alcançadas, como a da linguagem, da epistemologia, da história, os grandes temas filosóficos.

C\&E: O senhor falou de atividade. Ação e atividade tratam do mesmo assunto? Fazem parte do mesmo conceito? Poderíamos falar de uma teoria da atividade?

Schwartz: Hoje, está-se restringindo o conceito de ação de uma maneira que não me agrada. Pode-se entrar de muitas maneiras no conceito de ação. Claro que não se pode falar da mesma maneira da ação do indivíduo e da ação coletiva, por exemplo. Mas acredito que a noção de ação corre o risco de ser cortada, fracionada em uma seqüência delimitada em espaço e tempo, como uma seqüência de deliberação consciente, uma decisão e uma execução. 
Tudo isso existe, mas, se contemplarmos o que chamam de "as Teorias da Ação", vemos a tentativa de modelar essas seqüências através de padrões de raciocínios - por exemplo, a Filosofia Analítica, ou outras questões de relação enigmáticas nas ligações entre estados do cérebro e estados do pensamento -, de modelar estas relações num outro sentido. Porém, o fato de simplificá-las resulta na ambição de modelar tipos de seqüências. E desde que entremos neste processo, vamos mutilar o que se pode chamar de atividade. Mutilar porque, a partir do momento que se modela, se pretende antecipar o que acontecerá nesta seqüência. E isso vai eliminar o que me parece essencial: os conflitos internos, ou seja, os embates de normas, o que significa a presença de valores dentro da nossa atividade, e isto é o principal. O conceito de ação simplifica, dentro de espaço e tempo, processos, introduzindo a idéia de modelação de seqüências; mutila-se o principal, impede-se de ver o essencial, que são os debates de normas. Por isso, o conceito de atividade nos obriga a reconhecer as renormalizações das normas do fazer industrioso e a impossibilidade de se manipular a vida humana.

C\&E: O senhor criou na Universidade de Provence o Departamento de Ergologia. Poderia nos explicar do que se trata e que tipo de formação ele oferece? Schwartz: A iniciativa de criar esse departamento não foi nossa, mas uma sugestão do nosso reitor. Como nossas atividades têm sido desenvolvidas há 25 anos, contemplando esse tipo de preocupações e pesquisas, ele pensava em algo bem diferente dos outros departamentos. Algo dedicado a uma questão pluridisciplinar, o que não se poderia localizar ou resumir em uma disciplina particular, pois fazíamos uma abordagem multidisciplinar. Os alunos provinham de todas as profissões, era um meio de trabalho bem singular e, mais, tínhamos profissionais provenientes de várias áreas do saber. Essas três características conformavam tal singularidade, a partir das quais nosso reitor nos aconselhou a criar um departamento. Desenvolvemos uma plataforma de ensino voltada à especialização profissional, cuja base parte do interesse pela maneira de abordar a situação do trabalho em vários setores e também numa dimensão mais especulativa, conceitual, teórica, porque, como já disse, através do trabalho acontecem, desdobram-se muitas questões teóricas complexas. Desde então, propomos formação para profissionais, mesmo que não ligados a uma disciplina particular, mas com uma ambição profissional e/ou com atividades mais de pesquisa.

C\&E: O senhor disse que, desde o início, o perfil dos alunos é bastante multidisciplinar. Os profissionais de distintas áreas buscam o departamento como uma formação complementar especializada? Que tipos de profissionais?

Schwartz: Somos generalistas do trabalho, estamos problematizando conceitos, muitos dos quais atravessam todos os setores do trabalho. Obviamente temos de nos ajustar a situações bem diferentes, por isso não somos profissionais de um setor em particular, de um tipo de trabalho particular. É uma maneira de preparar os alunos. Prepará-los para enfrentar várias situações de formação 
profissional, competências, organização do trabalho, ergonomia ou atividade sindical. Esta hipótese se provou mais ou menos exata, coerente, um meio de intercâmbio entre vários setores, mas para melhor identificar os aspectos mais ou menos universais dentro do trabalho e dizer isto: "O fato de ser generalista do trabalho não traz nenhum inconveniente".

C\&E: O conjunto de professores que atuam no departamento tem perfis bastante diferenciados: há economistas, ergonomistas, educadores, pedagogos, engenheiros, entre outros profissionais. Qual é sua experiência de tratar com corpo acadêmico tão interdisciplinar?

Schwartz: No meu ponto de vista, facilita o trabalho em comum, apesar das competências, das especialidades distintas. No início, trabalhamos muito mais juntos, escutando uns aos outros. Agora, como já temos hábitos comuns, não é tão necessário. Seria melhor, mas não temos tempo. O que temos em comum é mais ou menos esse conceito de atividade, e isso nos conduz a reinterpretar, cada um, a nossa disciplina com essa noção transdisciplinar - mais do que antropológica - de uma filosofia da vida, o que nos impede de nos fecharmos sobre nós mesmos. Sabemos todos que, no uso de nossos conceitos disciplinares, temos de introduzir essa noção de renormatização. Um exemplo que sempre uso para ilustrar é que o ergonomista sabe que o trabalho prescrito nunca é igual ao trabalho real. Bom, o que isso significa para o lingüista? Quer dizer que, em todo lugar, sempre temos um coletivo real. Nunca é o mesmo que um coletivo prescrito; segundo, temos que nos perguntar como identificar essa entidade coletiva real que, como uma espécie de criação local, se fabrica, se estabiliza e fabrica os meios de sua atividade. Por exemplo, o lingüista vai estudar o lugar do trabalho, com esse coletivo de trabalhadores, e vai buscar os meios lingüísticos pelos quais transita essa fabricação. Assim, podemos ilustrar a maneira de trabalhar juntos do ergonomista e do lingüista. Poderíamos fazer o mesmo entre o ergonomista e o especialista da gestão, porque, se quisermos compreender a noção de gestão, precisamos entender que cada um, dentro de uma situação, não só executa as normas antecedentes, mas sempre as re-trabalha. Não se pode tratar a gestão, os conceitos de gestão, da mesma maneira. Aqui é possível entender a noção de atividade como essa universalidade de relação entre normas antecedentes e tentativas de renormatização.

C\&E: Ela perpassa todos os saberes, não é?

Schwartz: Exato, perpassa; e como temos de refratar todo o conceito de cada disciplina por meio da atividade humana, esse exercício muda os próprios conceitos. Há a necessidade de retrabalhar todos os conceitos através da imersão na atividade humana.

C\&E: Diria que é um exercício de fazer ciência no campo das Ciências Humanas?

Schwartz: Absolutamente, esse ponto de vista nos obriga a uma visão um pouco crítica. Claro que se pode discutir se é pertinente falar de Ciências Humanas; por isso, na pergunta anterior, acredito que não pode existir como ciência uma 
teoria da atividade. Porque a atividade sempre se desenvolve através de quadros. Por exemplo, entidades coletivas - mediante um mundo de debates de normas que se define num mundo de valores -, nunca podemos antecipá-las totalmente. A atividade sempre retrabalha o mundo do trabalho dentro do qual ela se desdobra e se moderniza. Não podemos fazer uma teoria da atividade, mas podemos identificar conceitos essenciais como a renormatização. Não é uma teoria, por isso não podemos falar em termos de Ciência. Na última semana, fui convidado para um seminário de sociólogos e falei precisamente do conceito de "entidade coletiva relativamente pertinente", porque, para os sociólogos, a noção de coletivo de trabalho é muito importante. Falei da idéia de que não se podia entender a cristalização desta "entidade" sem um mínimo de compartilhamento de valores; e a reação de um sociólogo foi a de questionar o que são valores? Ele disse só conhecer um sistema de valores. O regime ergológico diz que existe um jogo de valores dentro do ato do trabalho para arbitrar os debates de normas, mas não podemos dizer o que são esses valores, porque são sempre retrabalhados pela própria atividade. Esse sociólogo, para parecer científico, falava de um sistema de valores preexistente às pessoas e mais ou menos compartilhado por elas, como uma coisa bem estabilizada, bem formada, e que podia explicar e antecipar as relações entre as pessoas. Bom, um sistema de valores possibilita falar de Ciências Humanas, mas aqui há um ponto de discordância sobre essa idéia. Acredito que não podemos antecipar o mundo de valores que vai preponderar, ou exercer um papel nas decisões, nas arbitragens das normas. Podemos ter idéia, mas antecipar totalmente, isso não.

C\&E: O mundo do trabalho passou por muitas mudanças nas últimas duas décadas: as tecnologias de informação e de comunicação foram incorporadas, criou-se um novo meio ambiente informatizado e automatizado. O trabalho humano tornou-se mais desvalorizado com essas mudanças?

Schwartz: Poderíamos perguntar: por que desvalorizado? Ao contrário, se passarmos de um mundo mecânico a um com tecnologias sofisticadas, pode ser o contrário, mais valorizado - mas por que desvalorizado?

C\&E: Porque o homem é substituído pela máquina.

Schwartz: Quando ocorre essa mudança, às vezes, não sempre, é uma substituição de um trabalho humano que foi considerado simples, um pouco desvalorizado. Muita gente diz que o trabalho vai desaparecer com a automatização... No entanto, a realidade é que o trabalho não desaparece. A questão é como se enfrentam essas novas tecnologias. Parece que há uma grande diversidade de casos; pode ser um trabalho desvalorizado, retaylorizado, como o telemarketing, ou, até, a invenção de um novo computador. A manutenção dessas novas tecnologias pode ser bastante sofisticada e valorizada. Não existe uma resposta simples. O que acontece é que esse trabalho pode ser muito mais complicado de ser identificado, sobretudo através do que chamamos de serviços, porque não temos um produto produzido, concreto, com gestos que podem ser decompostos nessa atividade mais ou menos visível. Neste ponto podemos voltar aos atos e 
1. Nouroudine, Abdallah. Techniques et cultures. Comment s'appropriet-on des technologies transferées? (Técnicas e culturas: Qual o modo apropriado de transmitir tecnologias?) Toulouse: Octarès, 2001. às formas de inteligência do corpo; mas, para muitas atividades, as interações com as técnicas ou com as pessoas são muito mais difíceis de entender, de desvendar, de identificar, e isso pode revelar um motivo para a desvalorização. Quando se multiplicam as avaliações do trabalho, a partir dos resultados, é possível tornar invisível essa atividade; e isso é muito perigoso. Com a atividade mais gestual, corporal, rítmica, não se pode ignorar o engajamento da pessoa dentro do trabalho. Quando tratamos das tecnologias é muito mais difícil avaliar os tempos, o esforço exigido de alguém. Isso talvez explicasse uma das causas de desvalorização; não automaticamente, mas poderia.

C\&E: Tenho um exemplo para ilustrar essa pergunta. Operários metalúrgicos pintores de automóveis, quando cuidavam da pintura expondo seu próprio corpo aos danos, inclusive dos produtos químicos, se sentiam diretamente envolvidos com o trabalho. $\mathrm{O}$ avanço tecnológico proporcionou a criação de cabines de pintura onde robôs, manipulados a distância pelos trabalhadores, executam a tarefa. Eles dizem que são e que não são pintores, porque ficam atrás de um programa de computador, apertando botões para que um robô faça o trabalho. Eles se vêem como apertadores de botões! É a isso que o senhor se refere, no sentido de que essa atividade ficou mais na penumbra, não aparece porque ela não é corporal?

Schwartz: Isso me remete à tese de Abdallah Nouroudine ${ }^{1}$ sobre os pescadores que diziam gostar de ser pescadores-caçadores e as mudanças que lhes foram propostas, através da mobilização; é uma maneira de distingui-los, mas de suprimir uma ética do trabalho. Entendo bem essa atividade que fica na penumbra; desse ponto de vista, pode ser. Talvez o que falte aos trabalhadores, ou aos pintores, é que se vejam mais como técnicos, porque manipulam máquinas mais sofisticadas, que supõem um pouco de aprendizagem técnica, profissional, teórica. Não sei se para eles é uma desvalorização por completo.

C\&E: Significa ter outros conhecimentos.

Schwartz: Sim, claro, não sei...

C\&E: Noções de matemática, de leitura, manipulação e controle de cálculos. Schwartz: Exato, pode variar de acordo com as pessoas. De uma maneira ergológica, não podemos antecipar o que é bom, o que é melhor, o que não é melhor para as pessoas no trabalho. Podemos medianamente antecipar. Devemos sempre conservar uma parte de aprendizagem do que elas revelam a partir de seus valores. Encontramos uma situação semelhante numa fábrica de automóveis, com a substituição dos soldadores manuais por robôs. Às vezes, alguns preferem a situação anterior, outros não, porque há um melhora, uma promoção.

C\&E: Muitas profissões desapareceram e outras foram criadas nesse processo de mudança. Qual seu ponto de vista sobre a formação profissional nesse quadro de mudança? Qual o papel da universidade, da escola, das instituições de ensino nesse novo quadro?

Schwartz: Essa questão foi a origem da nossa história, porque já há 25 anos todo mundo falava de mudanças. Uma resposta simples seria dizer que é neces- 
sário conhecer melhor as mudanças do lado técnico, objetivo, como funciona um computador, uma nova máquina, e daí saber o que é o trabalho e que formações profissionais terão de ser desenvolvidas. Diria que essa resposta é simples demais. Essa visão é uma maneira de ficar cego com relação ao trabalho, à atividade de trabalho. Essas questões técnicas e profissionais não são diretamente a nossa responsabilidade, mas as instituições do saber têm de, ao mesmo tempo, se apropriar dessas novas tecnologias, o que chamo o ingrediente número um da competência; saberes antecipados, ou saberes desaderentes. Aquilo que podemos ensinar numa sala de aula e ao mesmo tempo acompanhar melhor como essas tecnologias são apropriadas na realidade. Uma tecnologia nunca pode ser abordada somente a partir de suas dimensões técnicas. Ela sempre requer uma atividade, e sempre é essa a dimensão que não podemos antecipar detalhadamente.

C\&E: Por exemplo, a formação de um adulto que está no mundo do trabalho. Como é que esse profissional pode ser recebido, ser visto e ser tratado numa instituição acadêmica? Como é esse encontro de saberes, em que ele tem que repensar, refletir, reconceituar o seu próprio trabalho, seu próprio meio profissional? Como o senhor vê esse encontro?

Schwartz: Exatamente, se não temos essas aproximações, não podemos entender do que se trata, como as coisas seguem e geram crises e dificuldades. Para mim é uma absoluta necessidade criar o que chamamos de Grupos de Encontro de Trabalho. O encontro daqueles que trabalham juntos e estão no entorno do trabalho, de um lugar de trabalho, de técnicas etc.; o encontro daqueles que enfrentam as técnicas, os meios de trabalho, os meios reais de trabalho e daqueles que vão fazer perguntas a partir dos conceitos um pouco mais gerais do que é trabalhar, do que é atividade. Para quê? Para gerar um outro olhar sobre o trabalho real e daí poder emergir os valores que se trabalham, retrabalham dentro dos meios da atividade. Certamente é uma primeira necessidade, mas é claro que não é fácil. A dificuldade ocorre porque a idéia é de que cada atividade humana sempre tem de arbitrar, de tomar decisões invisíveis e que o custo, a dificuldade, o sofrimento estão dentro da atividade. Essa não é uma idéia que se compartilhe facilmente, por várias razões. Razões científicas, porque não é mensurável, mas também por razões de status, porque isso desestabiliza o que é o saber, as ciências humanas etc.; e por razões políticas, porque cria outro olhar sobre o mundo do trabalho e traz problemas sobre a questão de hierarquia, de transmissão de objetivos, de estratégia de poder. É uma questão central - existe um lado de eficácia pedagógica e um lado de direção política, ou seja, o governo da humanidade por ela mesma.

C\&E: Nesse sistema de valores, o senhor comenta sempre os pólos dos valores mercantis, que são os preponderantes na atualidade, e também os valores sem dimensão, do viver bem em conjunto. Como harmonizar valores tão diferentes, mesmo nessa escala microssocial, na escala das relações de trabalho, das atividades? 
Schwartz: Harmonizar, não sei... O que me parece incontestável é que na realidade do trabalho assalariado, do trabalho que chamo trabalho stricto sensu, os dois tipos de valores agem juntos, mas não harmonizados, raramente. No entanto, se voltarmos à questão das entidades coletivas relativamente pertinentes, o que me parece absolutamente universal dentro de toda a situação do trabalho, tal entidade não pode ser mais ou menos pertinente, mais ou menos forte, mais ou menos estabilizada; podemos encontrar todos os tipos, todos os níveis, mas quando existem, significam sempre que as pessoas compartilham mais ou menos alguma coisa de valores em comum, senão não é possível e são espécies de valores sem dimensão, porque, se a pessoa vai a um escritório para pedir informação, se essa transmissão de informação se faz, pode-se fazer mais ou menos com vários graus; aqui intervém alguma coisa de valores não mercantis, o que não é uma relação prescrita...

C\&E: A pessoa não é obrigada.

Schwartz: Mas se isso não acontecer, rapidamente todas as relações se tornam problemáticas, porque, se não se tem o mínimo dessa entidade, não podemos trabalhar, nunca. Deste ponto de vista, os valores sem dimensão já estão mais ou menos na escala microssocial do trabalho. O problema é como a direção, em todos os níveis, inclusive no nível do Estado, trata desses valores sem dimensão; se vão restringi-los como um governo que prefere a individualização, a competição, a competitividade, que irá dar signos negativos ao alargamento desses valores sem dimensão na escala microssocial; ou, ao contrário, pode ser uma espécie de harmonização entre uma política global, ou em nível local. Há uma dialética, nos dois sentidos, entre o papel dos valores sem dimensão no nível microssocial e no nível macrossocial, porque a aderência dos valores sem dimensão dentro das criações de entidades muito fortes, estabilizadas - como um meio de vida feliz -, oferece credibilidade a uma política, inclusive ao Estado, pois se supõe que ele trate destes valores sem dimensão, por meio do qual a harmonização nunca é dada. Entretanto, esses dois tipos de valores estão implicados dentro de uma escala de direção e decisão do microssocial. 